Int. J. Appl. Radiat. Isot. Vol. 36. No. 8, pp. 672-674, 1985 (C) Pergamon Press Ltd 1985. Printed in Great Britain. $0020-708 \times / 85 \$ 3.00+0.00$

\section{A Captive Solvent Method for Rapid Radiosynthesis: Application to the Synthesis of [1-" C]Palmitic Acid}

\section{DOUGLAS M. JEWETT}

\section{RICHARD L. EHRENKAUFER and SIYA RAM}

Cyclotron/PET Facility, University of Michigan Medical School, Box 056, University Hospital, Ann Arbor, MI 48109, U.S.A.

(Receiced 4 December 1984; in revised form 25 February 1985)

A method is described for the synthesis of $\left[1-{ }^{11} \mathrm{C}\right]$ palmitic acid, in which " $\mathrm{CO}_{2}$ is reacted with a Grignard reagent trapped within the pores of microporous polypropylene powder in a column. The free acid is liberated by passing gaseous $\mathrm{HCl}$ through the column. The apparatus is very simple, facilitating automation and miniaturization of the synthesis.

\section{Introduction}

The availability of, and desirability for, an increasing number of positron-labeled radiopharmaceuticals for PET studies places stringent demands on the synthetic chemist. Most compounds must be synthesized each time they are needed, and often two or more agents must be delivered with precise timing. The necessary speed and reliability are achieved whenever possible by simplification both of synthetic schemes and of techniques. For example, the use of an immobilized hydrophobic phase, in the form of a cartridge of $\mathrm{C}_{18}$-bonded silica, to replace conventional liquid-liquid extraction ${ }^{(1.2)}$ appears to be generally applicable to syntheses on a submilligram scale.

Below we describe a "captive solvent" method, which appears likewise to be of broad applicability to the synthesis of compounds labeled with short-lived isotopes. In the method a reactant in a small volume of an appropriate solvent is held within the pores of a microporous, microparticulate solid packed in a column. A second reactant in a gas or immiscible liquid is passed through the column achieving thorough contact between the phases. In the synthesis of [1- "C]palmitic acid described below a Grignard reagent in tetrahydrofuran is contained within a column of microporous polypropylene powder through which " $\mathrm{CO}_{2}$ in $\mathrm{N}_{2}$ is passed. In general, a "captive solvent" method has the following features and possible advantages:

1. A dilute, gaseous, radiolabeled precursor such as " $\mathrm{CO}_{2}$ can easily be trapped in a very small volume of solution.

2. The need for the separation of two bulk immiscible phases is often eliminated.

3. The thermodynamic advantage of a column over a stirred reactor is realized, in that a product can be retarded on the column so that its concentration is very low in the reaction zone.

4. The "captive" reagents are contained in small, sealed cartridges, so that sensitive reagents may often be protected and stored for immediate demand. Such cartridges are well suited to automatic systems.

5. There is greater flexibility with respect to the type and volume of the immobilized phase than with bonded-phase silicas.

\section{Experimental}

\section{Cartridges of microporous polypropylene powder}

Porous polypropylene powder, $40 \mu \mathrm{m}$ (Accurel PP, Armak, Inc., Chicago) was washed with methylene chloride followed by ethanol and dried in a vacuum. Plastic syringes $(3 \mathrm{~mL}$ ) were cut off at the $2 \mathrm{~mL}$ mark, and small plugs of glass wool were pressed into the luer fittings. Polypropylene powder, $160 \mathrm{mg}$, was added and gently compacted with a rod to a volume of $1 \mathrm{~mL}$. Rubber septum caps were forced over the open ends and wired into place and 20 gage needles were fixed firmly on the luer fittings. (Fig. 1A.) The cartridges were stored in a vacuum desiccator over $\mathrm{P}_{2} \mathrm{O}_{3}$. At the time of use the desiccator was filled with $N_{2}$ before opening, and the ends of the needles were quickly inserted into rubber stoppers to keep the inert gas inside. Before the radiosynthesis the cartridges were filled with about $1 \mathrm{~mL}$ of $0.2 \mathrm{M}$ pentadecyl magnesium bromide in THF. All free liquid was blown out by a gentle stream of argon and the needles were immediately reinserted in the rubber stoppers to protect the reagent from the atmosphere. The volume of reagent retained on the columns was about $0.4 \mathrm{~mL}(0.08 \mathrm{mmol})$.

\section{Cartridges of alumina}

These were prepared in the same way as the polypropylene cartridges and contained $1.6 \mathrm{~g}$ neutral alumina (Biorad, AG7). Just before use the cartridges were washed with $25 \mathrm{~mL}$ of ether containing $0.15 \%$ HOAc. $^{(3.4)}$ In the experiments where ammoniated alumina is indicated, the alumina was exposed in a column to $\mathrm{NH}_{3}$ until evolution of heat ceased, and the column was then purged with $\mathrm{N}_{2}$.

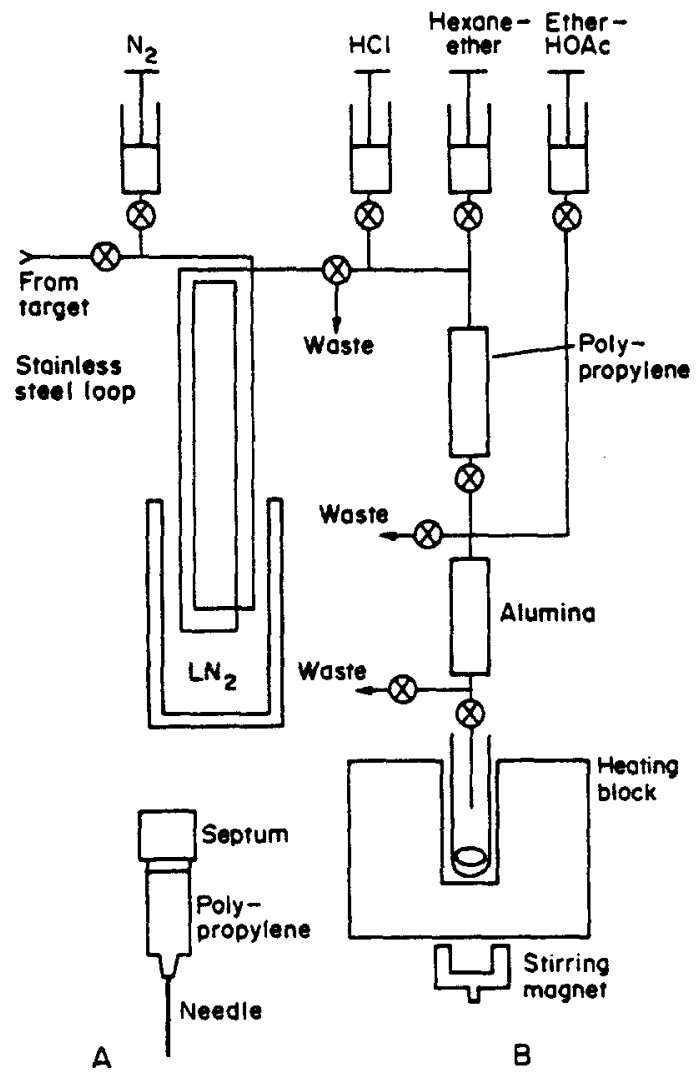

Fig. 1. A. Detail of construction of column containing polypropylene. B. Schematic diagram of apparatus for the synthesis of $[1-11$ C]palmitate. 
Where basic alumina is indicated, the alumina was washed with $1.0 \mathrm{~N} \mathrm{NaOH}$, rinsed well with water and dried at $100^{\circ} \mathrm{C}$. The columns of ammoniated and basic alumina were not washed with ether-HOAc before use.

\section{Radiosynthesis}

The apparatus and procedure are shown schematically in Fig. 1B. While symbols for valves are used at all connections to indicate the sequence of steps, in these experiments connections to the cartridges were made manually by inserting needles through septa. " $\mathrm{CO}_{2}$ was produced by the proton irradiation of nitrogen. ${ }^{(9)}$ After irradiation the target was vented rapidly through a loop half immersed in liquid nitrogen to trap the " $\mathrm{CO}_{3}$ quantitatively. ${ }^{(6)}$ The loop was warmed to room temperature, the " $\mathrm{CO}_{2}$ was purged with about $10 \mathrm{~mL} \mathrm{~N}$ into the cartridge containing the Grignard reagent, and this was followed by $25 \mathrm{~mL}$ of gaseous $\mathrm{HCl}$. The cartridge was purged with $100 \mathrm{~mL} \mathrm{~N}$ to remove excess $\mathrm{HCl}$. The outlet of the cartridge was then connected to a second cartridge containing alumina, and the product was eluted onto the alumina with $5 \mathrm{~mL}$ of ether-hexane, $4: 1$. The alumina was washed with $10 \mathrm{~mL}$ ether containing $1.5 \%$ acetic acid, and the effluent was evaporated instantly in a test tube equipped with a stirrer and maintained at about $70^{\circ} \mathrm{C}$.

\section{Analyses}

A portion of the product, dissolved in ether, was spotted on a silica plate with oleic acid as a reference, and developed with hexane-ether-HOAc, 95:5:1. The oleic acid was detected by iodine vapor. Relative radioactivity of the various zones was determined by $\gamma$-counting. After decay of the radioactivity the product was analyzed by GLC (OV-17) both before and after methylation with dimethylformamide dimethylacetal $^{(7)}$ to detect carrier palmitic acid and other volatile contaminants.

\section{Results and Discussion}

The results of ten experiments are presented in Table 1 . While further experiments are required to determine the best procedure for conditioning the alumina columns to permit simultaneous high recovery of the product and high purity, the method appears to offer a simple, reliable way to obtain [1-"C]palmitate in sufficient purity and quantity for PET studies in humans. For example, in experiment 8, $28 \mathrm{mCi}\left[1 .{ }^{11}\right.$ Clpalmitate (97.9\% radiochemical purity) was obtained in $12 \mathrm{~min}$ from $58 \mathrm{mCi}{ }^{1} \mathrm{CO}_{2}$. These and other experiments, which gave lower yields or purity, have allowed us to identify critical factors in the above method:

Preconcentration of the " $\mathrm{CO}_{2}$ is essential if the subsequent reaction is to take place in a very small volume of solvent. ${ }^{(6)}$ The elimination of this step has led to complications from the use of unnecessarily large amounts of Grignard reagent in some recently published syntheses of palmitic acid. ${ }^{(3.4)}$ Careful control of the volume and rate of purge of the trapped " $\mathrm{CO}_{2}$ into the cartridge containing the Grignard reagent is necessary for complete reaction of the former, e.g. experiment 5. The residual $\mathrm{HCl}$ must be thoroughly purged from the column by dry gas, so that it does not neutralize the very limited anion exchange capacity of the alumina.

It is possible (experiments 9 and 10), by the addition of a small amount of $\mathrm{CO}_{2}$ carrier, to suppress the formation of radioactive apolar by-products. It should also be possible to reduce the level of the latter by control of temperature and concentration of the Grignard reagent. If this can be done it will be possible to eliminate the alumina column, which irreversibly adsorbs a significant amount of the product.

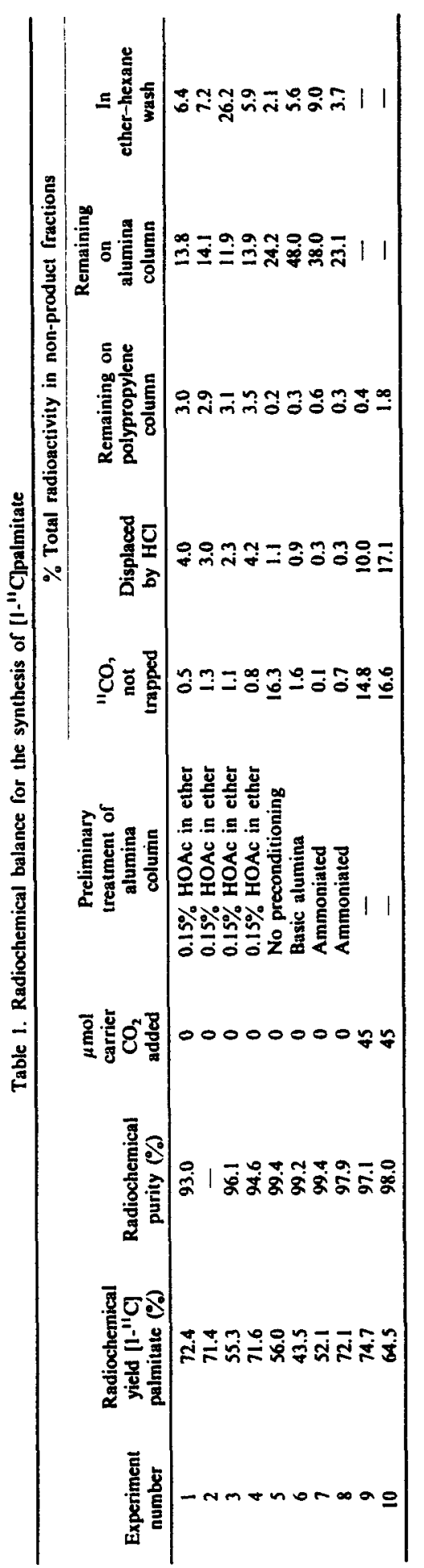


For the synthesis of $[1-"$ C]palmitic acid the "captive solvent" method appears to offer the following advantages:

1. There is little or no permanent apparatus to be cleaned or dried. Only a few minutes are required between syntheses to replace cartridges. Experiments $1-4$ were done by one person in a single $1.5 \mathrm{~h}$ period.

2. The number and size of components is very small, permitting simple shielding.

3. All movement of reactants and solvents can be handled simply by an automatic system. The "captive solvent" method eliminates both the need for a conventional gas-liquid reactor and for a liquid-liquid extraction, introducing considerable simplification in this regard.

4. The cartridges containing the "captive" Grignard reagent are hermetically sealed and stable for at least many hours at room temperature.

5. The amounts of Grignard reagent and accompanying solvent are very small, making purification of the product easier.

Solid phase supports other than polypropylene were also evaluated, but were less satisfactory than the latter. The above procedures were repeated using microporous cross linked polystyrene (Porapak $\mathrm{Q}$, Waters) and $\mathrm{C}_{18}$-bonded silica (Sep-Pak, Waters) as carriers for the Grignard reagent. The polystyrene strongly retained a large fraction of the product leading to a low radiochemical yield. While the Sep-Paks gave similar yields of $[1-" \mathrm{C}]$ palmitate as the polypropylene, the former were attacked significantly by the gaseous $\mathrm{HCl}$ leading to colored contaminants. Because polypropylene is inert toward most reagents and solvents, inherently dry because of a lack of polar groups and inexpensive, it appears to be, in general, the most satisfactory carrier for "captive solvent" techniques.

The use of "captive solvents" in chemistry is not new. It is the basis of conventional gas-liquid chromatography and was important in HPLC before the development of bondedphase silicas. Schwartz and Weihrauch used aqueous bisulfite adsorbed in a column of diatomaceous earth to extract traces of aldehydes from hexane. ${ }^{\left({ }^{\prime}\right)}$ There are, no doubt, many microchemical procedures that could benefit from greater solvent volumes and choice of solvent properties than are available with bonded-phase silicas. The availability of inexpensive microporous polypropylene promises to lead to further developments in this area.

Acknowledgements-This work was supported by Grant POI NS 15655 awarded by NINCDS, by Grant MH39331 awarded by NIMH and by Grant 5T32 CA09015 awarded by the National Cancer Insitute. We are indebted to Roger Lininger for the proton irradiations and to Diane Moxley for the sample of polypropylene powder.

\section{References}

1. Kilbourn M. R. and Welch M. J. Int. J. Appl. Radiat. Isot. 33, 359 (1982).

2. Adam M. J., Ruth T. J., Jivan S. and Pate B. D. Int. J. Appl. Radiat. Isot. 35, 985 (1984).

3. Padgett H. C., Robinson G. D. and Barrio J. R. Int. J. Appl. Radiat. Isot. 33, 1471 (1982).

4. Zielinski F. and Robinson G. Int. J. Nucl. Med. Biol. 11, 121 (1984).

5. Christman D. R., Finn R. D., Karlstrom K. I. and Wolf A. P. Int. J. Appl. Radiat. Isot. 26, 435 (1975).

6. Welch M. J., Dence C. S., Marshall D. R. and Kilboum M. R. J. Labeled Compd. Radiopharm. 20, 1087 (1983).

7. Thenot J. P. and Homing E. C. Anal. Lett. 5, 519 (1972).

8. Schwartz D. P. and Weihrauch J. L. Microchemical J. 18, 249 (1973). 